\title{
Reproductive parameters vary with social and ecological factors in the polygynous ant Formica exsecta
}

\author{
Rolf Kümmerli and Laurent Keller
}

R. Kümmerli (rolf.kuemmerli@ed.ac.uk) and L. Keller, Dept of Ecology and Evolution, Biophore, Univ. of Lausanne, CH-1015 Lausanne, Switzerland. Present address for RK: Inst. of Evolutionary Biology, Univ. of Edinburgh, West Mains Road, Edinburgh, UK, EH9 3JT.

\begin{abstract}
Due to their haplo-diploid sex determination system and the resulting conflict over optimal sex allocation between queens and workers, social Hymenoptera have become important model species to study variation in sex allocation. While many studies indeed reported sex allocation to be affected by social factors such as colony kin structure or queen number, others, however, found that sex allocation was impacted by ecological factors such as food availability. In this paper, we present one of the rare studies that simultaneously investigated the effects of social and ecological factors on social insect nest reproductive parameters (sex and reproductive allocation, nest productivity) across several years. We found that the sex ratio was extremely male biased in a polygynous (multiple queens per nest) population of the ant Formica exsecta. Nest-level sex allocation followed the pattern predicted by the queen-replenishment hypothesis, which holds that gynes (new queens) should only be produced and recruited in nests with low queen number (i.e. reduced local resource competition) to ensure nest survival. Accordingly, queen number (social factor) was the main determinant on whether a nest produced gynes or males. However, ecological factors had a large impact on nest productivity and therefore on a nest's resource pool, which determines the degree of local resource competition among co-breeding queens and at what threshold in queen number nests should switch from male to gyne production. Additionally, our genetic data revealed that gynes are recruited back to their parental nests after mating. However, our genetic data are also consistent with some adult queens dispersing on foot from nests where they were produced to nests that never produced queens. As worker production is reduced in gyne-producing nests, queen migration might be offset by workers moving in the other direction, leading to a nest network characterized by reproductive division of labour. Altogether our study shows that both, social and ecological factors can influence long-term nest reproductive strategies in insect societies.
\end{abstract}

Social Hymenoptera have become important model species to test kin-selection (Hamilton 1964) and sex-ratio theories (Fisher 1930). Hymenoptera have a haplodiploid sex determination system (Crozier 1971), which results in relatedness asymmetries such that females are more related to sisters $(r=0.75)$ than to daughters $(r=0.5)$, sons $(r=$ $0.5)$ or brothers $(r=0.25)$. Based on these relatedness asymmetries, workers in colonies with a single, once-mated queen should opt for a 3:1 female-biased sex ratio investment to maximize their inclusive fitness (i.e. the sum of the direct and indirect fitness effects of an individual's behaviour, where the indirect fitness effect is the impact on the fitness of its social partners weighted by the degree of relatedness between the individual and its social partners), whereas queens would benefit most from a 1:1 sex ratio (Trivers and Hare 1976). These different interests over colony sex ratio investment predict a conflict between queens and workers with the outcome depending on the power of workers or queens to control sex allocation (Chapuisat and Keller 1999, Beekman and Ratnieks 2003, Mehdiabadi et al. 2003).
The occurrence of multiple related queens per nest (polygyny) and/or of multiple matings per queen (polyandry) leads to a decrease in relatedness asymmetry. If relatedness asymmetry varies among colonies in a population, colony sex ratio is predicted to be split (Boomsma and Grafen 1990, 1991). This is because colonies having a relatedness asymmetry above the population average would benefit most from producing females while colonies with a relatedness asymmetry below the population average should primarily invest in males. Empirical data from a variety of species provided support for female biased sex ratios in species with a single, once-mated queen as well as for split sex-ratio theory in multiple-queen or multiple-mated queen societies (reviewed by Queller and Strassmann 1998, Chapuisat and Keller 1999, Bourke 2005). These data are consistent with the view that workers have some control over colony sex ratio investment. However, other studies have found split sex ratios in ants that were not correlated with relatedness asymmetry. These studies were consistent with queens controlling the colony sex ratio investment by laying only female or male eggs (Helms 1999, Passera et al. 2001, 
Fjerdingstad et al. 2002, Rosset and Chapuisat 2006) or with life-history parameters correlated with queen number and not colony kin structure per se being the determinant of colony sex ratio specialization (Brown and Keller 2000, Fournier et al. 2003, Kümmerli et al. 2005).

In addition to social factors such as kin structure or queen number, ecological factors have been shown to also impact colony sex allocation (Nonacs 1986, Rosenheim et al. 1996). For example, increased nest temperature leads to increased gyne (new queens) production in some ant species (Rosengren and Pamilo 1986, Aron et al. 1994). Moreover, experimental food supplementation in various ant species significantly increased the resources allocated to gynes (Deslippe and Savolainen 1995, Herbers and Banschbach 1998, Morales and Heithaus 1998, Bono and Herbers 2003, Brown and Keller 2006; see also Strohm and Linsenmair 1997, for similar results in the European beewolf), to males (Backus and Herbers 1992, Herbers and Banschbach 1999) or led to an increase in reproductive allocation (proportion of resources invested in sexuals versus workers: Backus 1995, Aron et al. 2001).

Studies on ecological factors influencing social Hymenoptera sex ratios have led to a debate on the extent to which sex ratio can be adaptive (Herbers 1979, Liautard et al. 2003) because random temporal and spatial fluctuations in ecological factors might impede adaptation. This view strongly contrasts with the apparent adaptive pattern of sex ratio based on variation in colony relatedness asymmetry and queen number (Queller and Strassmann 1998, Chapuisat and Keller 1999, Brown and Keller 2000, Bourke 2005). However, studies aiming at disentangling the effects of social and ecological factors on social insect resource allocation are scarce (Deslippe and Savolainen 1994, 1995, Brown and Keller 2000, 2006) with especially few data available on variation in reproductive parameters across several years. Thus, the aim of this study was to simultaneously investigate the effects of social and ecological factors on nest reproductive parameters (sex and reproductive allocation, nest productivity) in a polygynous population of the ant Formica exsecta across several years. Such knowledge is important because long-term reproductive strategies determine overall colony performance and hence are important life history traits of insect societies. Furthermore, conducting such a study on $F$. exsecta is of particular interest because this species has variable social organizations that are correlated with different sex allocation patterns. Specifically, in populations consisting of monogynous colonies split sex ratio was found to be correlated with variation in relatedness asymmetry (Sundström et al. 1996), while in populations consisting of polygynous colonies split sex ratio was found to be correlated with variation in queen number but not relatedness asymmetry (Brown and Keller 2000, Kümmerli et al. 2005). Moreover, in polygynous populations random temporal fluctuations of ecological factors have been suggested to lead to non-adaptive temporal variation in sex ratios (Liautard et al. 2003).

Previous studies on polygynous $F$. exsecta populations showed that variation in nest sex allocation is consistent with the queen-replenishment hypothesis, which proposes that nests containing many queens should only produce males, whereas nests hosting few queens should produce gynes in addition to males (Brown and Keller 2000, 2002, Kümmerli et al. 2005). This hypothesis is based on the observation that in highly polygynous species, queen dispersal is often limited with young newly-mated queens being recruited back into their parental nest (Bourke and Franks 1995, Keller 1995). This mode of reproduction may lead to intense local resource competition and is often associated with extremely male-biased sex ratios (Bourke and Franks 1995, Crozier and Pamilo 1996). According to the queen-replenishment hypothesis, nests containing relatively few queens are those benefiting most from recruiting new queens because local resource competition is reduced. Hence, below a certain threshold in queen number, colonies are egg-limited and there is a premium on recruiting new queens to enhance nest survival and productivity with this threshold depending on the resource availability relative to the current number of queens. Because queens live for several years (Keller and Genoud 1997), queen recruitment probably shifts queen number above the threshold for several consecutive years and queen production is therefore expected to be a rare event in a nest's life cycle.

The queen replenishment hypothesis leads to predictions of how queen number and nest productivity should vary across years (Table 1). Firstly, queen number should increase in nests producing gynes due to queen recruitment, whereas queen mortality should lead to a gradual decrease over years in queen number in nests producing no gynes. We tested these predictions by following variation in queen number across four years. Secondly, nest productivity should increase after queen recruitment because nests having produced gynes should no longer be egg-limited. This prediction was not supported in a two-year study (Brown and Keller 2002) but it remained possible that it might take more than one year for the positive effect of greater queen number on nest productivity to be visible (due to initial tradeoffs with the production of workers). Here, we tested whether queen production indeed comes at the expense of worker production and whether there was a delayed positive effect of queen production on nest productivity. Finally, productivity per queen is predicted to decrease in the year after queen recruitment because nests having recruited new queens should no longer be limited by

Table 1. Predictions of the queen replenishment hypothesis on variation in queen number, nest productivity and productivity per queen across several years. 2a: if gyne production does not occur at the cost of worker production. $2 \mathrm{~b}$ : if gyne production occurs at the cost of worker production and nests suffer from a shortage in the worker force in the year following gyne production.

\begin{tabular}{llccc}
\hline & Variable & Year of queen production & 1 year after queen production & 2 and more years after queen production \\
\hline 1 & queen number & low & high & decreasing \\
$2 \mathrm{a}$ & nest productivity & low & high & decreasing \\
$2 \mathrm{~b}$ & nest productivity & low & low & high \\
3 & productivity per queen & high & low & increasing \\
\hline
\end{tabular}


the rate at which eggs are laid and thus reproductive success of individual queens will be constrained by the availability of other resources. By contrast, productivity per queen should gradually increase in the years after queen recruitment as queen number decreases and nests become more and more egg limited, thus, increasing the reproductive success of individual queens. We tested these predictions by following variation in productivity per queen across three years.

In addition, we tested whether ecological factors impacted the important parameters of the queen replenishment hypothesis (i.e. queen number and nest productivity). This is important because the threshold in queen number determining whether a nest should produce gynes (i.e. nests that are egg-limited) or males (i.e. nests that are constraint by other resources than eggs) depends on resource availability, which itself might depend on ecological factors. In line with this idea, experimental food supplementation significantly increased the proportion of nests producing gynes (Brown and Keller 2006), suggesting that a greater resource pool stimulates the production of gynes. However, because little is known about the ecological factors affecting this resource pool, we tested whether natural variation in the nests' exposure to sunshine, nest density, nest area and the distance to natural honeydew-bearing aphid locations impacted nest queen number, nest productivity and the number of years a nest produced gynes.

\section{Material and methods}

\section{Study site and focal colonies}

We studied a population of Formica exsecta that has been previously used for sex allocation studies (Brown and Keller 2002, Brown et al. 2002, Liautard et al. 2003). The population is located at les Chenevières, a cattle pasture at $1220 \mathrm{~m}$ in the Swiss Jura Mountains. At this site, nests (defined as spatially separated ant domes) are known to be polygynous (Cherix et al. 1980, Brown and Keller 2000) and nest sex ratio is highly male-biased with about $90 \%$ of the nests producing only males and workers (Brown and Keller 2000). Within female-producing nests, dry-mass investment in gynes is between $41.4 \%$ and $70.7 \%$ (range across five years, Brown and Keller 2002, this study). Queen number ranges from a few to several hundred individuals (arithmetic mean $=115.8$, harmonic mean $=23.6$, Liautard et al. pers. comm.). The estimated harmonic mean queen number matched well our estimate of the genetically effective number of queens contributing to brood production $\left(\mathrm{N}_{\mathrm{e}}=23.7\right.$, mean across male- and female-producing nests, Kümmerli and Keller 2007b). The mean effective mating frequency of queens has been estimated to be 1.2 (Liautard et al. pers. comm.). Furthermore, data from a population genetic analysis are consistent with $65 \%$ of the queens having mated with a nestmate male, while $35 \%$ of queens mate with a random male from the same population (Kümmerli and Keller 2007a). Although this population has been intensively studied, nests were only moderately disturbed. Specifically, the main impact on nests between 1996 and 2001 was that every year we sampled 50 pupae and a comparable number of workers from the mounds. As this treatment was applied to almost all nests within the population and nests generally produce thousands of new offspring every year, previous manipulation should not have influenced the results of the present study.

Although workers in polygynous $F$. exsecta populations seem to migrate freely between nests (Cherix et al. 1980, Katzerke et al. 2006, hence forming a unicolonial population structure), a recent genetic study (Kümmerli and Keller 2007a) provides evidence that queens form extended family-based groups leading the relatedness values among worker pupae that are significantly greater than zero. For that reason, we considered each nest as an independent data point. However, as colony boundaries are difficult to define in this species, we consistently use the word "nest" when referring to individual ant domes. In $F$. exsecta, no brood overwinters and thus brood emerging in summer derives from eggs laid earlier that same year (Brown and Keller 2002). In 2002, we individually marked 411 nests and measured their investment into gynes, males and workers for three consecutive years (2002-2004). Out of these 411 nests, we randomly selected 24 female- and 24 maleproducing focal nests, for which we measured productivity (2002-2004) and genetically effective queen number (2002-2005). To be able to distinguish between femaleand male-producing nests prior to brood emergence in June 2002, we surveyed all 411 nests for the presence of large pupae, which indicates gyne production. However, one focal nest classified as male producing produced only workers in 2002 and was excluded from further analysis.

\section{Nest-level reproductive allocation and sex allocation}

From each of the 411 nests where brood was available (a considerable number of nests did not produce any brood in one or several years, Table 2), we collected approximately 50 pupae prior to the first brood emergence in July 2002, June 2003 and July 2004. For each year and nest, we determined the proportion of gynes, males and workers in this sample by moistening the collected pupae in ethanol and observing the size, eye shape and genitalia of late-stage pupa (Brown and Keller 2000, Liautard et al. 2003). We quantified reproductive allocation as the proportional dry weight investment into sexuals by dividing the number of sexuals (gynes and males) produced by the total number of offspring in the sample (gynes, males and workers) weighted by their relative dry mass (Brown and Keller 2000).

Because we were interested in the causes underlying the decision to produce gynes (or not), we classified, as in

Table 2. Years of brood and gyne production for 347 nests that survived the three study years. ${ }^{*}$ these nests produced workers and/or males.

\begin{tabular}{lrrrrr}
\hline \multirow{2}{*}{$\begin{array}{l}\text { Years of brood } \\
\text { production }\end{array}$} & \multirow{2}{*}{$\begin{array}{c}\text { No. of } \\
\text { nests }\end{array}$} & \multicolumn{4}{c}{ Years of gyne production } \\
\cline { 3 - 6 } & & None* & 1 year & 2 years & 3 years \\
\hline None & 46 & - & - & - & - \\
$\begin{array}{l}1 \\
\text { year }\end{array}$ & 21 & 14 & 7 & - & - \\
2 years & 50 & 31 & 15 & 4 & - \\
3 years & 230 & 166 & 56 & 7 & 1 \\
Sum & 347 & 211 & 78 & 11 & 1 \\
\hline
\end{tabular}


previous studies (Brown and Keller 2000, 2002, Brown et al. 2002, Liautard et al. 2003, Kümmerli et al. 2005), nests as male-producing if they produced males (along with workers) but no gynes, and female-producing, if they produced gynes (usually along with workers and males).

\section{Nest productivity}

We estimated brood production in the 47 focal nests using the mark-recapture methods described by Sundström (1995). In 2002, we repeatedly measured brood production in July (before brood emergence), August and September by marking a total of 27122 (July), 33780 (August) and 27955 (September) pupae with a different colour for each period. In 2003 and 2004, we estimated brood production only during the main period of brood production (July) where we marked a total of 31726 (2003) and 28490 (2004) pupae. We collected between 8 and 3125 pupae per nest (there was great variance in brood production among nests) from beneath the nest surface and marked them individually with a dot of ink from a non-toxic, permanent colour marker. The pupae were then returned into the nest after gently opening the surface. Two to four days later, we captured another sample of pupae and used the proportion of marked to unmarked pupae to estimate the total number of pupae within the nest. We calculated nest productivity in grams as the sum of the number of gynes, males and workers times their respective dry mass (Brown and Keller 2000).

\section{Genetically effective queen number}

Because nests of $F$. exsecta are voluminous and contain many queens, it is difficult to directly count the number of queens present in a nest. We therefore estimated the genetically effective number of queens that corresponds to the number of equally reproducing queens required to account for an observed relatedness pattern (Queller 1993b). To obtain estimates of relatedness among brood, we genotyped eight worker pupae from each focal nest and year at six highly polymorphic microsatellite loci (FL21 (Chapuisat 1996), FE17, FE19, FE21, FE37 and FE51 (Gyllenstrand et al. 2002). We used PCR-amplification and electrophoresis procedures described in Kümmerli et al. (2005). We estimated relatedness among female brood $\left(\mathrm{r}_{\mathrm{f}}\right)$ within a nest with the program RELATEDNESS 5.0.8 (Queller and Goodnight 1989) and then calculated the genetically effective queen number $\left(\mathrm{N}_{\mathrm{e}, \mathrm{g}}\right)$ using the formula

$\mathrm{N}_{\mathrm{e}, \mathrm{g}}=\frac{4 \mathrm{r}_{\mathrm{s}}-\mathrm{r}_{\mathrm{q}}-2 \mathrm{r}_{\mathrm{m} 1}}{4 \mathrm{r}_{\mathrm{f}}-\mathrm{r}_{\mathrm{q}}-2 \mathrm{r}_{\mathrm{m} 1}}$

where $r_{s}$ is the relatedness among female offspring of the same matriline, $r_{q}$ is the relatedness among nestmate queens and $r_{m 1}$ is the relatedness among the mates of nestmate queens (Seppä 1994). The relatedness among female offspring of the same matriline $\left(r_{s}\right)$ is $1 /\left(2 m_{e}\right)+1 / 4$, where $m_{e}$ is the mean effective mating frequency of queens in the nest (Queller 1993b). In our study population, $\mathrm{r}_{\mathrm{q}}, \mathrm{r}_{\mathrm{m} 1}$ and $\mathrm{m}_{\mathrm{e}}$ have been estimated to be $0.084 \pm 0.006$ (mean \pm SE), $0.020 \pm 0.003$ $($ mean \pm SE) and 1.2 , respectively (Liautard et al. pers. comm.). Repeated samples of worker pupae for the years 2002-2005 were available from 16 nests that produced gynes in 2002 followed by at least two years of male production (three nests produced again gynes in 2005), and 15 nests that produced only males and workers during the entire study period.

\section{Ecological factors}

We measured four ecological factors for all of the 411 nests in 2002. First, we quantified the daily exposure to sunshine, which is probably an important factor influencing reproductive parameters because $F$. exsecta prefers open and sun exposed habitats (Maggini et al. 2002). We estimated the number of hours each nest was exposed to sunshine between 08:00 am and 08:00 pm on July 22 and 23 in 2002 by checking each nest once every half hour for the presence of sunshine on the nest surface. Second, we measured the nest area by taking two measures of the nest diameter at right angles, which were then used to calculate the area of an ellipse $(\pi \mathrm{ab} / 4$, where $\mathrm{a}$ and $\mathrm{b}$ correspond to the two diameters measured). The edge of the nest was defined as the limit of the area denuded of vegetation by the ants (Brown et al. 2002). We measured nest area in each of the three years and took the average nest area for statistical analyses. Third, we quantified for each nest a density index (d) that includes information on the number of surrounding nests, their area and distance relative to the focal nest within a maximal distance of 20 meters:

$$
\mathrm{d}=\sum_{\mathrm{i}=1}^{\mathrm{n}} \frac{\mathrm{s}_{\mathrm{i}}}{\mathrm{l}_{\mathrm{i}}^{2} \mathrm{~s}_{\mathrm{f}}}
$$

where $l_{i}$ is the distance between the focal nest and the ith surrounding nest, whereas $s_{\mathrm{i}}$ and $s_{\mathrm{f}}$ are the nest areas of the ith surrounding and the focal nest, respectively. Finally, because aphid honeydew collectable from trees is an important natural food resource for $F$. exsecta (Brown and Keller 2006), we assessed whether a nest was close to the forest (distance $\leq 10 \mathrm{~m}$ ) or far from forest (distance $>10 \mathrm{~m}$ ). These arbitrary chosen distance categories lead to comparable numbers of nests in each category (far: $\mathrm{n}=150$, close: $\mathrm{n}=197)$ and are based on the observation that $F$. exsecta workers generally forage within a short distance around the nest (Pisarski 1982) with access to honeybearing aphids being mostly limited to nests being close to the forest.

\section{Statistical analysis}

The dependent variables in our statistical models were the number of years a nest produced gynes and brood (values from 0 to 3), the nest's proportional and absolute dry weight investment into sexuals or workers, the nest productivity, the productivity per queen and the genetically effective queen number. Continuous independent variables, which were treated as covariates in our models, were the number of sunshine hours per day, nest density index and nest area. Factorial independent variables were the distance category of nests to the forest (far/close) and the nest type (female- or male-producing). Whenever repeated measures 
were taken on the same nest (across years or months), we added the nest ID as a blocking factor into our model (Sokal and Rohlf 1995). When comparing productivity between female- and male-producing nests, we included nest area as a covariate into our statistical models. This is because nest productivity was associated with nest area (see our results in Table 3 and Brown et al. 2002) and focal female-producing nests were found to be significantly smaller $\left(\mathrm{n}=24\right.$, median $=2651 \mathrm{~cm}^{2}$, range: $542-8749$ $\left.\mathrm{cm}^{2}\right)$ than focal male-producing nests $(\mathrm{n}=23$, median $=$ $2839 \mathrm{~cm}^{2}$, range: $823-12733 \mathrm{~cm}^{2}$; repeated measures ANOVA permutation test: $\mathrm{n}=47, \mathrm{p}=0.001$ ).

In nests hosting many queens, the relatedness among brood is low and the estimated values can sometimes be negative due to stochastic sampling errors arising from the limited number of loci and pupae genotyped. Such negative values lead to large negative estimates of genetically effective queen number. To cope with this problem, we applied the reciprocal transformation $1 / \mathrm{X}$ to all estimates of effective queen number $\left(\mathrm{N}_{\mathrm{e}, \mathrm{g}}=\mathrm{X}\right.$ ) prior to statistical analyses (Sokal and Rohlf 1995). This transformation yields a linear relationship between relatedness values and the reciprocals of the effective queen number, with the transformed values ranging from around zero (low or slightly negative relatedness values) to one (high relatedness values).

Because we had no a priori criteria on the order the four ecological factors should be entered into the model, we tested all factors relative to the full model using the single term deletion procedure (Faraway 2005). In this procedure, the relationship between the dependent variable and only a single ecological factor is tested at a time, whilst controlling for the variance explained by all other ecological factors on the dependent variable and the correlations between independent variables. Indeed, several ecological factors were significantly correlated with each other. While most correlations were weak (Spearman's rank coefficient $-0.29<\mathrm{r}_{\mathrm{s}}<-0.02, \mathrm{n}=347$ ), highly significant associations occurred between nest area and nest density $\left(r_{s}=-0.48, n=347, p<0.001\right)$ and between exposure to sunshine and distance to forest $\left(r_{s}=-0.53, n=347\right.$, $\mathrm{p}<0.001)$.

We used permutation test statistics (Manly 1997) for all analyses. This was because some dependent variables were discrete (number of years a nest produced gynes or brood) or because the dependant variables deviated significantly from normal distributions even after logarithmic transformations (Shapiro-Wilks-test: $\mathrm{p}<0.05$ ). Before conducting permutations, we first applied parametric statistical computations on our data set (i.e. analyses of variance (ANOVA) when only factors were included and analyses of co-variance (ANCOVA) when the model also included covariates).
From these analyses, we extracted the obtained F-values that we classified as the observed values of our analysis $\left(\mathrm{F}_{\mathrm{obs}}\right)$. We then performed 1000 random permutations on our data set and calculated the F-values after each permutation using the computer program R 2.2.0 (available on http:// www.r-project.org/). These permutations provided us with randomized distributions of $\mathrm{F}$-values towards which the observed F-values could be compared. The probability of getting $\mathrm{F}$-values that are greater or equal to the observed F-values is given by $\mathrm{p}=\left(1+\mathrm{n}_{\mathrm{F}} \geq\right.$ Fobs $) / 1000$, where $\mathrm{n}_{\mathrm{F}} \geq$ Fobs is the number of cases in which $\mathrm{F}$-values obtained from the permutation were greater or equal than the observed F-values (Manly 1997). We regarded p-values $\leq 0.05$ as significant. For post hoc multiple comparisons, we used the false discovery rate (FDR) control method (Benjamini and Hochberg 1995) to adjust the nominal $\alpha$ of $5 \%$. As the threshold $\mathrm{p}$-value for the FDR control changes for each analysis and comparison, we generally present raw p-values and only report the exact FDR control probability threshold $\left(p_{F D R}\right)$ when $p$-values $\leq 0.05$ became insignificant after applying the FDR control.

\section{Results}

\section{General patterns of reproductive allocation and sex allocation}

Of the 411 surveyed nests, 53 were abandoned during the three-year study and 11 were destroyed by human agricultural activities. The other 347 nests survived the entire study period and were used for data analysis with the numbers of years these nests produced brood and gynes being given in Table 2.

In all three years, most resources were allocated to workers $(41.0 \%-62.5 \%)$ or to males $(31.4 \%-50.8 \%)$, while only a low proportion of resources were allocated to gynes $(1.1 \%-8.2 \%$; Fig. 1$)$. The mean $( \pm$ SE) proportional investment into sexuals was $37.5 \% \pm 1.9 \%$ (2002), $37.2 \% \pm 1.6 \%$ (2003), and $59.0 \% \pm 1.8 \%$ (2004) and differed significantly between years (repeated measures ANOVA permutation test: $\mathrm{n}=230, \mathrm{p}=0.001$ ).

As predicted by the queen-replenishment hypothesis, most nests $(n=155,71.1 \%)$ specialized in male production during the three consecutive years or produced gynes only once during three years $(\mathrm{n}=55,25.2 \%)$. Only eight nests $(3.7 \%)$ produced gynes in two or three years (Table 2$)$. The number of nests producing gynes differed significantly between years $\left(\chi^{2}=11.7, \mathrm{DF}=2, \mathrm{p}=0.003\right)$ and was 41 $(14.7 \%)$ in $2002,19(6.9 \%)$ in 2003 and $43(16.8 \%)$ in 2004.

Table 3. Associations between reproductive parameters and ecological factors.

\begin{tabular}{|c|c|c|c|c|c|}
\hline \multirow[t]{2}{*}{ Reproductive parameter } & \multirow[t]{2}{*}{$\mathrm{n}$} & \multicolumn{4}{|c|}{ Ecological factors } \\
\hline & & Sunshine hours per day & Nest area & Distance to the forest & Nest density index \\
\hline No. of years a nest produced gynes & 230 & negative* & $\mathrm{x}$ & $x$ & $\mathrm{x}$ \\
\hline Genetically effective queen number & 43 & positive** & $\mathrm{x}$ & $x$ & $x$ \\
\hline Nest productivity & 47 & positive* $^{*}$ & positive* $^{*}$ & $\mathrm{x}$ & $\mathrm{x}$ \\
\hline No. of years a nest produced brood & 347 & positive $\mathrm{e}^{* * *}$ & positive $\mathrm{e}^{* * *}$ & far $>$ close $\mathrm{e}^{* * *}$ & $x$ \\
\hline
\end{tabular}

${ }^{*} \mathrm{p} \leq 0.05,{ }^{* *} \mathrm{p} \leq 0.01,{ }^{* * *} \mathrm{p} \leq 0.001, \mathrm{x}=$ no significant association. 


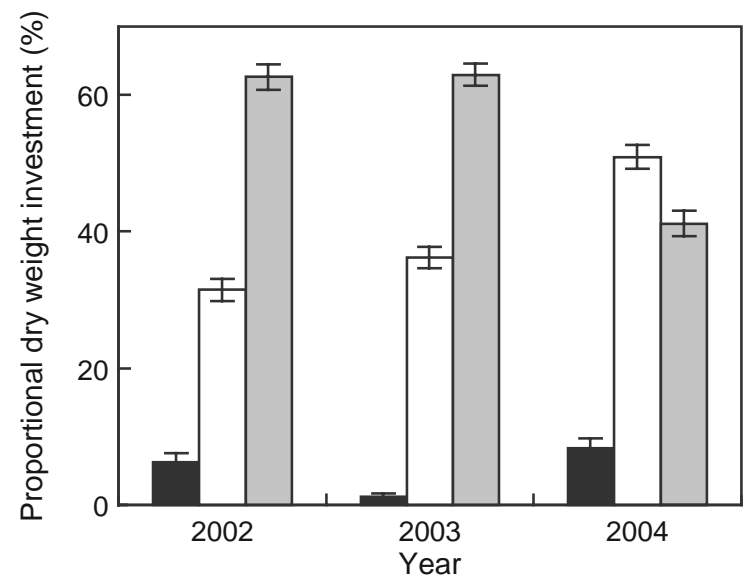

Fig. 1. Proportional dry weight investment (mean $\pm S E$ ) into gynes (black bars), males (white bars) and workers (grey bars) for the 230 nests that produced brood in all three study years.

The number of years a nest produced gynes was significantly negatively associated with the number of sunshine hours per day (ANCOVA permutation test: $\mathrm{n}=230, \mathrm{p}=0.014$, Table 3 ), while there were no significant associations with the nest area, the distance to the forest and the nest density index (ANCOVA permutation test: $n=230$, nest area: $p=0.71$, distance class to forest: $\mathrm{p}=0.82$, nest density: $\mathrm{p}=0.11$ ).

\section{Variation of queen number across years}

Relatedness estimates among worker pupae were low for all years in both female- and male-producing nests (range: $0.02-0.15)$ indicating that nests generally contained multiple queens. Across the entire study period, there were significant differences in the genetically effective queen numbers between female- and male-producing nests (Fig. 2) with a significant interaction between year and sex ratio specialization (repeated measures ANOVA permutation test: $\mathrm{n}=31$, sex ratio specialization: $\mathrm{p}=0.018$, year: $\mathrm{p}=$ 0.47 , interaction: $p=0.004)$. Post hoc comparisons showed that the genetically effective queen number was significantly smaller in female- $\left(\mathrm{N}_{\mathrm{e}}=5.6\right)$ than in male- $\left(\mathrm{N}_{\mathrm{e}}=110.1\right)$ producing nests in $2002(\mathrm{p}=0.007)$. The opposite pattern was observed in 2003, where the genetically effective queen number was marginally significantly greater in nest that produced females in $2002\left(\mathrm{~N}_{\mathrm{e}}=172.8\right)$ compared to nests that produced males in $2002\left(\mathrm{~N}_{\mathrm{e}}=8.8, \mathrm{p}=0.061\right)$, whereas there were no significant differences between the two categories of nests in $2004(\mathrm{p}=0.16)$ and 2005 ( $\mathrm{p}=$ 0.15 ). When analysing female-producing nests separately, we found that the genetically effective queen number followed the temporal pattern predicted by the queenreplenishment hypothesis (Fig. 2). In the year following gyne production, the effective queen number significantly increased (repeated measures ANOVA permutation test, $\mathrm{n}=16$, comparison 2002/2003: $\mathrm{p}=0.023$; becomes marginally insignificant after the FDR control with $\mathrm{p}_{\mathrm{FDR}}=$ 0.017 ) and then decreased in 2004 and 2005 but with these estimates not being significantly different from the estimate in 2003 (repeated measures ANOVA permutation test, $\mathrm{n}=16$, comparison 2003/2004: $\mathrm{p}=0.07$, comparison

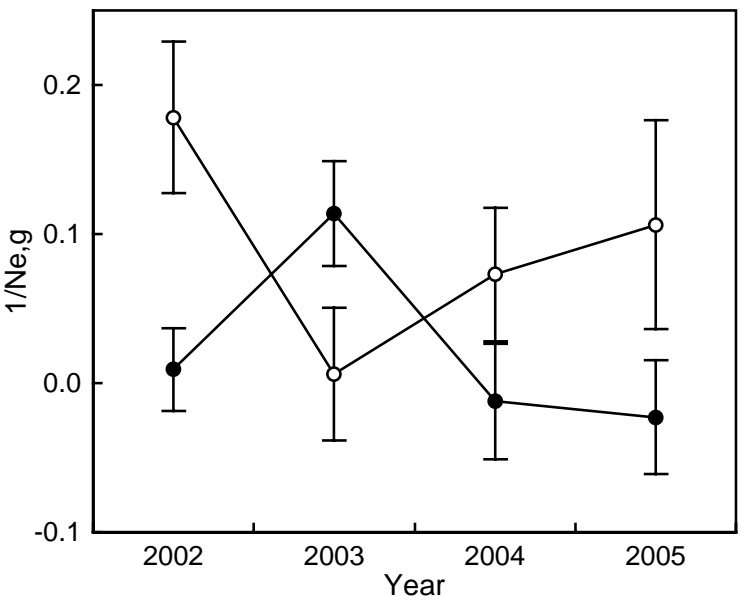

Fig. 2. Variation of the genetically effective queen number (mean \pm SE) across years in female-producing nests (open circles, these nests produced females in 2002 and then switched to male production in the following years) and male-producing nests (closed circles, these nests produced only male sexuals across the entire study period). Estimates of the genetically effective queen number $\left(\mathrm{N}_{\mathrm{e}, \mathrm{g}}\right)$ are presented as transformed values $\left(1 / \mathrm{N}_{\mathrm{e}, \mathrm{g}}\right)$ with high transformed values corresponding to low queen numbers and low transformed values corresponding to high queen numbers. Slightly negative values can arise in colonies hosting many queens due to stochastic sampling errors arising from limited number of loci and pupae genotyped.

2003/2005: $p=0.28$ ). When analysing male-producing nests separately, we also found that the genetically effective queen number significantly varied across years (repeated measures ANOVA permutation test, $\mathrm{n}=15, \mathrm{p}=0.021$, Fig. 2).

The genetically effective queen number was significantly positively associated with the number of sunshine hours per day (ANCOVA permutation test: $\mathrm{n}=43, \mathrm{p}=0.004$, Table 3 ) while there was no significant association with nest area, the distance of nests to the forest and nest density index (ANCOVA permutation tests: $n=43$, nest area: $p=0.09$, distance to the forest: $p=0.10$, nest density: $p=0.55$ ). We repeated this analysis by only including female-producing nests to test for an association between ecological factors and the threshold in effective queen number at which nests switch from male to gyne production. There was a significant positive correlation between the threshold in effective queen number and the number of sunshine hours per day (ANCOVA permutation test: $\mathrm{n}=22, \mathrm{p}=0.024$ ), while there were no significant correlations with the nest area, the distance of nests to the forest and nest density index (ANCOVA permutation tests: $\mathrm{n}=22$, nest area: $\mathrm{p}=$ 0.15 , distance to the forest: $\mathrm{p}=0.08$, nest density: $\mathrm{p}=$ $0.18)$.

\section{Pattern of resource allocation across months}

The dry weight investment into workers was significantly different between female- and male- producing nests across the three study months in 2002 (July, August and September; repeated measures ANCOVA permutation test: $n=47$, sex ratio specialization: $\mathrm{p}=0.001$, month: $\mathrm{p}=0.10$, interaction: $\mathrm{p}=0.22$, Fig. 3) with female-producing nests consistently 


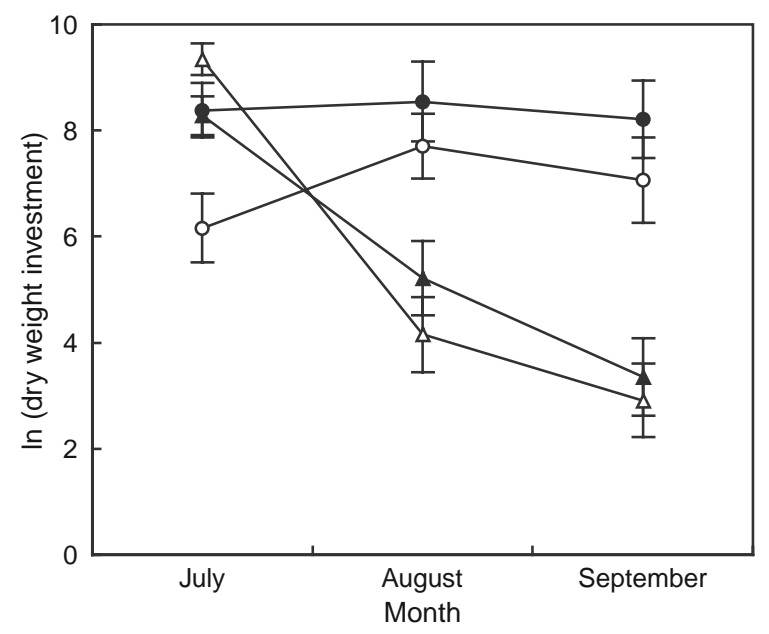

Fig. 3. Comparison of dry weight investment (logarithmic transformed values in $\mathrm{mg}$, mean $\pm \mathrm{SE}$ ) to worker offspring (circles) and sexual offspring (triangles) in female-producing nests (open symbols) and male-producing nests (closed symbols) in 2002.

investing fewer resources into workers than male-producing nests. In contrast, dry weight investment into sexuals did not significantly differ between male- and female-producing nests but significantly varied between the three study months (July, August and September, repeated measures ANCOVA permutation test: $n=47$, sex specialization: $p=0.71$, month: $\mathrm{p}=0.001$, interaction: $\mathrm{p}=0.15$, Fig. 3).

\section{Pattern of nest productivity across years}

There were significant differences in the total productivity between female- and male-producing nests and between years with a significant interaction between these two variables (repeated measures ANCOVA permutation test: $\mathrm{n}=47$, sex ratio specialization: $\mathrm{p}=0.001$, year: $\mathrm{p}=0.006$, interaction: $p=0.006$, Fig. 4a). Post hoc comparisons

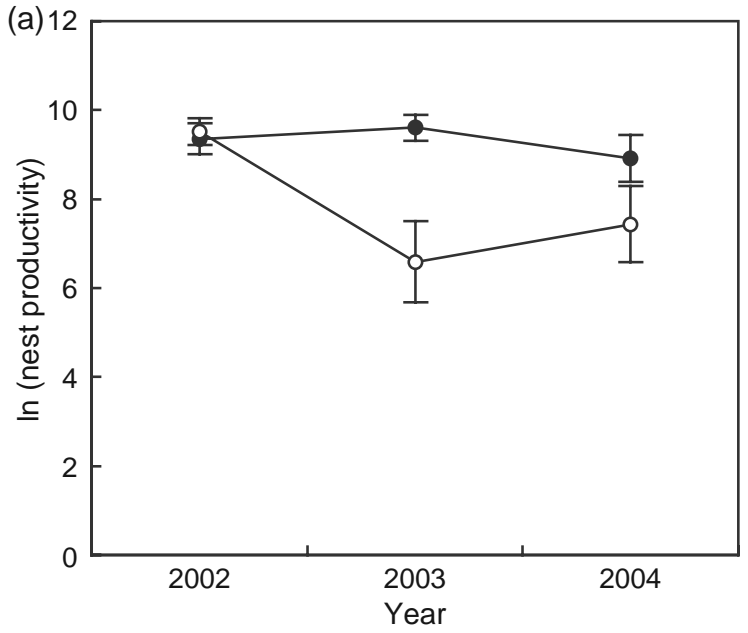

showed that total productivity was significantly lower in female- than in male-producing nests in $2003(\mathrm{p}=0.003)$, but not in $2002(\mathrm{p}=0.71)$ and $2004(\mathrm{p}=0.13)$. When conducting separate comparisons for female- and maleproducing colonies, productivity significantly varied between years in female- but not in male-producing nests (ANCOVA permutation test, female-producing nests: $\mathrm{n}=$ 24, $\mathrm{p}=0.003$; male-producing nests: $\mathrm{n}=23, \mathrm{p}=0.26$ ). Post hoc comparisons for female-producing nests showed that productivity was significantly lower in 2003 and 2004 than in 2002 (ANCOVA permutation test, 2002/2003: $\mathrm{p}=0.004 ; 2002 / 2004: \mathrm{p}=0.012)$, while there was no significant difference between 2003 and $2004(\mathrm{p}=0.29)$.

Nest productivity significantly increased with the number of sunshine hours per day and nest area (ANCOVA permutation test: $n=47$, sunshine hours per day: $p=$ 0.014 , nest area: $p=0.020$, Table 3 ). However, there were no significant associations between the productivity and the distance of nests to the forest or nest density index (ANCOVA permutation test: $\mathrm{n}=47$, distance to forest: $p=0.72$, nest density: $p=0.84$ ).

Another measure of productivity is the number of years a nest produced brood, which was significantly higher for nests being far from the forest $(>10 \mathrm{~m}, \mathrm{n}=150)$ than for nests being close to the forest $(<10 \mathrm{~m}, \mathrm{n}=197)$ and significantly increased with the number of sunshine hours per day and nest area (ANCOVA permutation test: $\mathrm{n}=347$, sunshine hours per day: $\mathrm{p}=0.001$, nest area: $\mathrm{p}=0.001$, distance class to forest: $\mathrm{p}=0.001$, Table 3). There was no significant association between the number of years a nests produced brood and the nest density index (ANCOVA permutation test: $\mathrm{n}=347$, nest density: $\mathrm{p}=0.18$, Table 3 ).

\section{Variation of productivity per queen across years}

There was a significant interaction between years and the sex ratio specialization in the productivity per queen

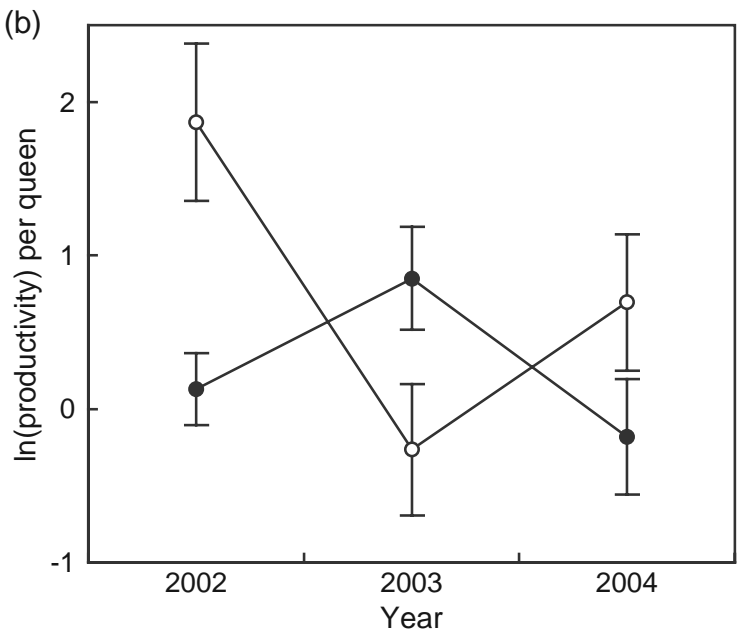

Fig. 4. Variation of (a) nest productivity and (b) productivity per queen across years in female-producing nests (open circles; these nests produced females in 2002 and then switched to male production in the following years) and male-producing nests (closed circles; these nests produced only male sexuals across the entire study period). Productivities (mean \pm SE) are given as logarithmic transformed dry weight investments in $\mathrm{mg}$. Slightly negative values can arise in colonies hosting many queens due to stochastic sampling errors arising from limited number of loci and pupae genotyped. 
(repeated measures ANCOVA permutation test: $\mathrm{n}=31$, sex ratio specialization: $p=0.091$, year: $p=0.090$, interaction: $\mathrm{p}=0.001$, Fig. 4b). Post hoc comparisons revealed that productivity per queen was higher in female- than in maleproducing nests in 2002 ( $\mathrm{p}=0.008$ ), while no differences in productivity per queen was found in 2003 ( $p=0.043$, insignificant after the FDR control with $\left.\mathrm{p}_{\mathrm{FDR}}=0.033\right)$ and $2004(p=0.14)$. Furthermore, productivity per queen differed significantly across years in female-producing colonies (repeated measures ANCOVA permutation test: $\mathrm{n}=16, \mathrm{p}=0.013$ ) with productivity per queen being significantly lower in 2003 (the year after gyne production) than in 2002 (post hoc comparison $\mathrm{p}=0.013$ ).

\section{Discussion}

Reproductive allocation, sex allocation and productivity varied greatly between nests in our three-year study in a polygynous population of the ant Formica exsecta. We found that these variations were significantly associated with both the number of queens per nest (social factor) and ecological factors.

The associations between nest queen number and sex allocation were consistent with predictions of the queenreplenishment hypothesis. The queen-replenishment hypothesis holds that nests containing many queens are subject to intense local resource competition and should only produce male sexuals (i.e. the dispersing sex), whereas local resource competition is reduced in nests hosting few queens and below a certain threshold there is a premium on producing and recruiting new queens to avoid brood limitation. Because queen recruitment probably shifts queen number above the threshold for several consecutive years, queen production is expected to be a rare event in a nest's life cycle. Our data clearly support these ideas, showing that the genetically effective queen number was significantly lower in female- than in male-producing nests and the majority of nests produced gynes in none $(71 \%)$ or in only one $(25 \%)$ out of three years with the population sex ratio being extremely male biased in all three study years (Fig. 1). Furthermore, the genetically effective queen number showed the predicted pattern of temporal variation. Specifically, queen number was lowest in the year of gyne production, highest in the year after gyne production and decreased constantly from then onwards presumably due to queen mortality and because no new queens were recruited (Fig. 2). If nests were followed over many more years, the observed pattern of temporal variation should repeat itself, thus leading to cyclical patterns of queen numbers across years.

Our data also provide information on ecological factors possibly influencing the threshold in queen number where nests should switch from male to gyne production. We found that the threshold in effective queen number in female-producing nests was significantly higher in nests with more intense exposure to sunshine. Because exposure to sunshine was found to be positively correlated with nest productivity and the number of years a nest produced brood, sunny nests probably have access to more resources and thus benefit from shifting earlier to gyne production (i.e. more queens are necessary to produce sufficient number of eggs).

If gyne production is the only way to recruit new queens, queen number should constantly decrease over time due to queen mortality in nests that produce only males. Our estimates of the genetically effective queen number in maleproducing nests indeed showed that queen number decreased between 2002 and 2003, but then surprisingly increased again in 2004 and 2005 (Fig. 2). This suggests that these nests recruited queens without having produced gynes themselves. This is somewhat surprising because a previous study showed that male-producing nests killed a high proportion of gynes (73\%-98\%) when these were experimentally introduced (Brown et al. 2003). However, it is possible that an increase in queen number occurred via acceptance of adult reproductive queens dispersing on foot between nests rather than the recruitment of gynes after mating flight. This would be possible because femaleproducing nests always produce an excess of new queens (Brown et al. 2003). However, even if some migration by adult queens occurs from female- to male-producing nests, the strong genetic differentiation between nests at mtDNA markers (Liautard and Keller 2001) suggests that the rate of migration is limited. Altogether, our data seem to be best explained by gyne recruitment occurring mostly at the nest level, while excess queens might migrate to nearby colonies later in their life. This pattern would be consistent with a low but significant genetic structuring among nests (Kümmerli and Keller 2007a) and the evidence based on genetic data that experimentally introduced adult queens were accepted and allowed to reproduce in foreign nests (Kümmerli et al. 2005).

The queen-replenishment hypothesis further predicts that if low queen number causes brood limitation, queen recruitment should result in increased overall nest productivity, but only if gyne production does not come at the expense of worker production (Table 1, Brown and Keller 2002). However, we could now show that gyne production indeed came at the expense of worker production with female-producing nests allocating significantly fewer resources to worker production than male-producing nests (Fig. 3). Furthermore, this reduced investment into workers in female-producing nests was associated with a significant decrease in overall nest productivity in the first and the second year after gyne production (Fig. 4a). These findings indicate that the relationship between queen number and nest productivity is more complex than previously thought with queen recruitment not leading to an immediate increase in nest productivity. However, our data show the tendency of a slight increase in nest productivity between the first and the second year after gyne production, with nest productivity being no longer different from that in male-producing nests (Fig. 4a). This pattern may indicate that nest productivity recovers slowly after gyne production and may eventually, after a few years, attain a higher level than the one before gyne production.

We could also show that brood production (nest productivity and the number of years a nest produced brood) was highly influenced by several ecological factors, whereby brood production increased with exposure to sunshine and nest area and decreased with close proximity to the forest. Our finding that nests closer to the forest 
produced brood less frequently is surprising given that theses nests should have access to a supplementary food source (honeydew). However, proximity to the forest was strongly negatively associated with exposure to sunshine. Thus, the benefit of increased food might be outweighed by the negative effects associated with reduced exposure to sunshine, which emphasizes the importance of exposure to sunshine as a factor influencing reproductive parameters in F. exsecta.

Finally, the queen-replenishment hypothesis predicts that queen recruitment should lead to a decrease in the productivity per queen. This is because nests having recruited new queens should no longer be brood limited and thus the productivity per queen should be constrained by other resources. Our data are in full agreement with this prediction by showing that productivity per queen decreased significantly in the year following gyne production (Fig. 4b). Furthermore, productivity per queen increased in the second year after gyne production, which conforms to the predicted pattern of temporal variation (Table 1).

While a previous two-year-study (Brown and Keller 2002) tested the basic predictions of the queen-replenishment theory, our data provide significant new insights into the pattern of gyne production and recruitment in a system where related co-breeding queens compete for common resources (local resource competition). First, while this and Brown and Keller's (2002) study both show that queen number increased in the year after gyne production, we could further demonstrate that queen number decreased in the second and third year after gyne production thereby following the predicted pattern of temporal variation across years. This is important because it suggests the beginning of a predicted cyclical pattern of queen number across years. Although such cyclical patterns have been reported in other social insect species (four species of epiponine wasps; Queller 1993a, and another ant Myrmica sulcinodis, Elmes 1987), this is the first study that provides evidence for queen number and recruitment being associated with the degree of local resource competition among co-breeding queens. Second, we found sex allocation to be correlated with resource allocation, whereby gyne production came at the cost of worker production. This is important because a reduction in the worker force also reduces a nest's potential for resource acquisition and therefore further increases local resource competition between queens. Third, we show that ecological factors (e.g. exposure to sunshine) were significantly associated with nest productivity and with the threshold in queen number at which nests switch from male- to gyne-production. This indicates that ecological factors impact a nest's resource pool, which would then determine the level of local resource competition among queens. For example, for a given number of queens, local resource competition can be strong in a resource-poor nest (hence resulting in male production) whereas local resource competition might be low in a resource-rich nest (hence resulting in gyne production). Finally, we found evidence that gyne production is not the only mechanism to recruit new queens as queen number also varied in nests that produced only males across four years. This suggests that two types of nests exist with one type following cyclical patterns of gyne production and recruitment across years, whereas the other type consists of nests producing only males while recruiting queens from nearby nests. Because worker production is reduced in female-producing nests, the migration of gynes from female- to male-producing nests might be offset by worker moving in the other direction, hence leading to a nest network characterized by a reproductive division of labour.

In conclusion, the observed pattern of split sex ratio, which is associated with the level of local resource competition among co-breeding queens, seems to be adaptive in $F$. exsecta, which adds to the increasing body of work demonstrating that extreme sex ratios can arise when relatives interact (Bourke and Franks 1995, West et al. 2005). However, although it is often possible (as in our study) to predict sex ratio variation across different breeders or nests, it is much more difficult to predict population sex ratios (West and Sheldon 2002). Population sex ratio seems also difficult to predict in our study where reproductive and sex allocation varied significantly across years (Fig. 1). Such variation might be due to unpredictable climatic fluctuations (Liautard et al. 2003) such as the summer 2003, which was exceptionally hot and dry. These exceptional weather conditions were associated with very little or no gyne production in this and another $F$. exsecta population (Kümmerli et al. 2005), a sex ratio that is presumably nonadaptive.

Acknowledgements - We thank William Brown, Michel Chapuisat, Rob Hammond and Matthew Ayres for constructive comments on the manuscript. We are grateful to Grégoire Castella, Susanne Kümmerli-Schildknecht and Michi Ringli for their help in the field and in the laboratory. Many thanks to Cathy Haag-Liautard for providing unpublished data. This work was supported by several grants from the Swiss National Science Foundation.

\section{References}

Aron, S. et al. 1994. Queen-worker conflict over sex ratio: a comparison of primary and secondary sex ratios in the Argentine ant, Iridomyrmex humilis.. - J. Evol. Biol. 7: 403418.

Aron, S. et al. 2001. Role of resource availability on sex, caste and reproductive allocation ratio in the Argentine ant Linepthema humile.. - J. Anim. Ecol. 70: 831-839.

Backus, V. L. 1995. Rules for allocation in a temperate forest ant: demography, natural selection, and queen-worker conflict. - Am. Nat. 145: 775-796.

Backus, V. L. and Herbers, J. M. 1992. Sexual allocation ratios in forest ants: food limitation does not explain observed patterns. - Behav. Ecol. Sociobiol. 30: 425-429.

Beekman, M. and Ratnieks, F. L. W. 2003. Power over reproduction in social Hymenoptera. - Philos. Trans. R. Soc. Lond. B 358: 1741-1753.

Benjamini, Y. and Hochberg, Y. 1995. Controlling the false discovery rate: a pratical and powerful approach to multiple testing. - J. R. Stat. Soc. A 57: 289-300.

Bono, J. M. and Herbers, J. M. 2003. Proximate and ultimate control of sex ratios in Myrmica brevispinosa colonies. - Proc. R. Soc. Lond. B 270: 811-817.

Boomsma, J. J. and Grafen, A. 1990. Intraspecific variation in ant sex ratios and the Trivers-Hare hypothesis. - Evolution 44: 1026-1034.

Boomsma, J. J. and Grafen, A. 1991. Colony-level sex ratio selection in the eusocial Hymenoptera. - J. Evol. Biol. 4: 383407. 
Bourke, A. F. G. 2005. Genetics, relatedness and social behaviour in insect societies. - In: Fellowes, M. D. E. et al. (eds), Insect evolutionary ecology. Proc. R. Entomol. Soc. 22nd Symp. CABI Publishing.

Bourke, A. F. G. and Franks, N. R. 1995. Social evolution in ants. - Princeton Univ. Press.

Brown, W. and Keller, L. 2000. Colony sex ratios vary with queen number but not relatedness asymmetry in the ant Formica exsecta. - Proc. R. Soc. Lond. B 267: 1751-1757.

Brown, W. D. and Keller, L. 2002. Queen recruitment and split sex ratios in polygynous colonies of the wood ant Formica exsecta. - Ecol. Lett. 5: 102-109.

Brown, W. D. and Keller, L. 2006. Resource supplements cause a change in colony sex-ratio specialization in the moundbuilding ant, Formica exsecta. - Behav. Ecol. Sociobiol. 60: 612-618.

Brown, W. D. et al. 2002. Sex allocation in mound-building ants: the roles of resources and queen replenishment. - Ecology 83: 1945-1952.

Brown, W. D. et al. 2003. Sex-ratio dependent execution of queens in polygynous colonies of the ant Formica exsecta. - Oecologia 134: 12-17.

Chapuisat, M. 1996. Characterization of microsatellite loci in Formica lugubris $B$ and their variability in other ant species. - Mol. Ecol. 5: 599-601.

Chapuisat, M. and Keller, L. 1999. Testing kin selection with sex allocation data in eusocial Hymenoptera. - Heredity 82: 473478.

Cherix, D. et al. 1980. Organisation spatiale d'un système polycalique chez Formica (Coptoformica) exsecta Nyl. (Hymenoptera: Formicidae). - Mitt. Schweiz. Ent. Ges. 53: 163-171.

Crozier, R. 1971. Heterozygosity and sex determination in haplodiploidy. - Am. Nat. 105: 399-412.

Crozier, R. and Pamilo, P. 1996. Evolution of social insect colonies: sex allocation and kin selection. - Oxford Univ. Press.

Deslippe, R. J. and Savolainen, R. 1994. Role of food supply in structuring a population of Formica ants. - J. Anim. Ecol. 63: 756-764.

Deslippe, R. J. and Savolainen, R. 1995. Sex investment in a social insect: the proximate role of food. - Ecology 76: 375382.

Elmes, G. W. 1987. Temporal variation in colony populations of the ant Myrmica sulcinodis. I. Changes in queen number, worker number and spring production. - J. Anim. Ecol. 56: 559-571.

Faraway, J. J. 2005. Linear models with R. - Chapman \& Hall.

Fisher, R. A. 1930. The genetical theory of natural selection. - In: Bennett, J. H. (ed.), The genetical theory of natural selection, a complete, variorum edition. Oxford Univ. Press.

Fjerdingstad, E. J. et al. 2002. Why do some social insect queens mate with several males? Testing the sex ratio manipulation hypothesis in Lasius niger. - Evolution 56: 553-562.

Fournier, D. et al. 2003. Colony sex ratios vary with breeding system but not relatedness asymmetry in the facultatively polygynous ant Pheidole pallidula. - Evolution 57: 13361342.

Gyllenstrand, N. et al. 2002. Polymorphic microsatellite DNA markers in the ant Formica exsecta. - Mol. Ecol. Notes 2: 6769.

Hamilton, W. D. 1964. The genetical evolution of social behaviour. - J. Theor. Biol. 7: 1-52.

Helms, K. R. 1999. Colony sex ratios, conflict between queens and workers, and apparent queen control in the ant Pheidole desertorum. - Evolution 53: 1470-1478.

Herbers, J. M. 1979. The evolution of sex-ratio strategies in hymenopteran societies. - Am. Nat. : 818 114: 834.
Herbers, J. M. and Banschbach, V. S. 1998. Food supply and reproductive allocation in forest ants: repeated experiments give different results. - Oikos 83: 145-151.

Herbers, J. M. and Banschbach, V. S. 1999. Plasticity of social organization in a forest ant species. - Behav. Ecol. Sociobiol. 45: 451-465.

Katzerke, A. et al. 2006. Seasonal nestmate recognitionin the ant Formica exsecta. - Behav. Ecol. Sociobiol. 61: 143-150.

Keller, L. 1995. Social life: the paradox of multiple-queen colonies. - Trends Ecol. Evol. 10: 355-360.

Keller, L. and Genoud, M. 1997. Extraordinary lifespans in ants: a test of evolutionary theories of ageing. - Nature 389: 958-960.

Kümmerli, R. and Keller, L. 2007a. Contrasting population genetic structure for workers and queens in the putatively unicolonial ant Formica exsecta. - Mol. Ecol. 16: 4493-4503.

Kümmerli, R. and Keller, L. 2007b. Reproductive specialization among nestmate queens in the polygynous ant Formica exsecta. - Behav. Ecol. 18: 375-383.

Kümmerli, R. et al. 2005. Experimental manipulation of queen number affects colony sex ratio investment in the highly polygynous ant Formica exsecta. - Proc. R. Soc. Lond. B 272: 1789-1794.

Liautard, C. and Keller, L. 2001. Restricted effective queen dispersal at a microgeographic scale in polygynous populations of the ant Formica exsecta. - Evolution 55: 2484-2492.

Liautard, C. et al. 2003. Temporal and spatial variations of gyne production in the ant Formica exsecta. - Oecologia 136: 558 564.

Maggini, R. et al. 2002. A stratified approach for modeling the distribution of a threatened ant species in the Swiss National Park. - Biodiv. Conserv. 11: 2117-2141.

Manly, B. F. J. 1997. Randomization, bootstrap and Monte Carlo methods in biology. - Chapman and Hall.

Mehdiabadi, N. J. et al. 2003. Queens versus workers: sex-ratio conflict in eusocial Hymenopera. - Trends Ecol. Evol. 18: 8893.

Morales, M. A. and Heithaus, E. R. 1998. Food from seeddispersal mutualism shifts sex ratios in colonies of the ant Aphaenogasteer rudis. - Ecology 79: 734-739.

Nonacs, P. 1986. Sex-ratio determination within colonies of ants. - Evolution 40: 199-204.

Passera, L. et al. 2001. Queen control of sex ratio in fire ants. - Science 293: 1308-1310.

Pisarski, B. 1982. Structure et organisation des sociétés de fourmis de l'espèce Formica (Coptoformica) exsecta Nyl. (Hymenoptera, Formicidae). - Memorabilia Zool. 38: 1-280.

Queller, D. C. 1993a. A selfish strategy of social insect workers that promotes social cohesion. - Nature 365: 639-641.

Queller, D. C. 1993b. Genetic relatedness and its components in polygynous colonies of social insects. - In: Keller, L. (ed.), Queen number and sociality in insects. Oxford Univ. Press, pp. 132-152.

Queller, D. C. and Goodnight, K. F. 1989. Estimating relatedness using genetic markers. - Evolution 43: 258-275.

Queller, D. C. and Strassmann, J. E. 1998. Kin selection and social insects. - Bioscience 48: 165-175.

Rosengren, R. and Pamilo, P. 1986. Sex ratio strategy as related to queen number, dispersal behaviour and habitat quality in Formica ants. - Entomol. Generalis 11: 139-151.

Rosenheim, J. A. et al. 1996. Sex ratio and multifaceted parental investment. - Am. Nat. 148: 501-535.

Rosset, H. and Chapuisat, M. 2006. Sex allocation conflict in ants: when the queen rules. - Curr. Biol. 16: 328-331.

Seppä, P. 1994. Sociogenetic organization of the ants Myrmica ruginodis and Myrmica lobicornis: number, relatedness and longevity of reproducing individuals. - J. Evol. Biol. 7: 71-95. 
Sokal, R. R. and Rohlf, F. J. 1995. Biometry. - W. H. Freeman and Company.

Strohm, E. and Linsenmair, K. E. 1997. Low resource availability causes extremely male-biased investment ratios in the European beewolf, Philanthus triangulum F. (Hymenoptera, Sphecidae). - Proc. R. Soc. Lond. B 264: 423-429.

Sundström, L. 1995. Sex allocation and colony maintenance in monogyne and polygyne colonies of Formica truncorum (Hymenoptera: Formicidae): the impact of kinship and mating structure. - Am. Nat. 146: 182-201.
Sundström, L. et al. 1996. Conditional manipulation of sex ratios by ant workers: a test of kin selection theory. - Science 274 : 993-995.

Trivers, R. L. and Hare, H. 1976. Haplodiploidy and the evolution of the social insects. - Science 191: 249-263.

West, S. A. and Sheldon, B. C. 2002. Constraints in the evolution of sex ratio adjustment. - Science 295: 1685-1688.

West, S. A. et al. 2005. Sex-ratio adjustment when relatives interact: a test of constraints on adaptation. - Evolution 59: 1211-1228. 